\title{
Increasing Students' Graphic Awareness, from Activities of Converting a Situation-Context into Their Graphical Representation
}

\author{
Marcelino Caetano Luís \\ Department of Natural Science and Mathematics, Pedagogical University of Mozambique, Mozambique
}

\begin{abstract}
How to cite this paper: Luís, M. C. (2018) Increasing Students' Graphic Awareness, from Activities of Converting a SituationContext into Their Graphical Representation. The Educational Review, USA, 2(6), 330-338. http://dx.doi.org/10.26855/er.2018.06.002
\end{abstract}

Corresponding author: Marcelino Caetano Luís, Ph.D., Department of Natural Science and Mathematics, Pedagogical University of Mozambique, Mozambique.

\begin{abstract}
The conversion is an activity that leads to the mechanisms of the understanding in mathematics. In this perspective, this study aims to evaluate the effectiveness that the conversion activities of a situation-context have, for the growth of the graphic awareness. The research was carried out through a questionnaire submitted to 30 students of the Mathematics and Physics courses of the Pedagogical University. The activities of the questionnaire were to convert a situation-context into a graphic sketch, from the identification of relevant cognitive variables. The individual results of the tasks show that students generally have difficulties in converting a situation-context into a graphic sketch, with a strong influence of the "semantic congruence" factor in their thoughts. But, taken together and comparatively, the results revealed that there has been a significant increase in students' graphic awareness. Indeed, as one goes from one task to another, it has been found that student performance has increased by an average of about $16 \%$, which leads to the conclusion that the activities of converting a situation-context into a graph, increase the students' graphic awareness.
\end{abstract}

\section{Keywords}

Situation-Context, Conversion, Graphic Awareness, Graph, Semantic Conguence, Increase

\section{Introduction}

Studying functions and their representations is so important today, because much information on social phenomena, socioeconomic, physical, etc., is disseminated by the media through graphics. This is why Braga (2006) considers that the concept of function is the soul of mathematics teaching. To understand such information one needs to have a sufficiently developed graphic awareness.

However, despite the importance of the concept of function in many areas of knowledge, and this merit a formal special attention in school mathematics, seems to prevail even in students who complete high school and even some secondary school teachers, cognitive difficulties related to this concept, and these difficulties are revealed more when it comes especially to convert a situation of a real context into graphical representation.

That is was I found with my students of the 1st year of physics in the first half of 2015, when I introduced the topic named generalities of real functions. It was given a real situation-context task, and the students were asked to build a graphic sketch that best represented the change of distance as a function of time. None of the students manage to give a reasonable answer to 
the question. The same difficulty was observed with $90 \%$ of a group of secondary school teachers attending the 3rd year of Distance Mathematics Education.

According to da Silva (2007), it seems that many of the students that end the average level lost the fundamental ideas about the concept and the behaviour of the function. Consequently, they cannot produce a mental image of the graphical representation of a real context.

Everything that the students learned about functions at the secondary and high school, it seems that was not significant for the development of their graphic awareness. Why does this happen?

We must understand 'graphic awareness' as the subject's ability to know and directly perceive the critical variables and languages of structuring of a graph in relation to the quantities and languages involved in the situation-context.

According to Duval (2011), the deep reason students did not develop a graphic awareness, should not be sought in the mathematical concepts related to functions, but in the lack of understanding about the links between the graphical representation semiotic registries and situation-context. It was in this perspective that this study was conducted.

This study aims to understand how the graphic awareness in the students can increase, when put into activities that lead them to abstract a visual image of the operation of converting a situation-context, from several alternatives of cognitive variables given in order to convert a situation-context to a graphic register.

\section{Theoretical Background}

Conventional approaches on the graphing instruction is for marking and connecting some points in the cartesian system from a table of values obtained by calculations of an analytical expression. Bell \& Janvier (1981) points out that this form of approach about graph of function, not explicit in advance the kind of change that is intended; because a function is more than one object of ordered pairs. 'Function' should be understood as "a definite connection between two things, called variables, that, when one is changing, the other also changes or does not change" (p. 35).

Probably these conventional approaches are one of the causes of the difficulties that the majority of students present when facing tasks of interpreting graphs, and the difficulties are increased when, specifically, the task is about representing a situation-context by a graphic. According to Silva (2007), most students have shown great difficulty in graphical sketching of a problem situation without resorting to their law of formation, that is, the algebric expression. Costa (2010) refers to the work of Tairab \& Al-Naqbi (2004), who found that students can perform better when the task is to interpret, but poor performance when the task is to sketch graphs (Costa, 2010, p. 139).

However, students' performance on tasks of creating graphics can improve considerably if the approaches to teaching function involves at least the interpretation of graphs representing situation-context. Bell \& Javier (1981) found that graphical approaches with contexts improve the development of "graphic awareness" (p. 41).

Indeed, according to Costa (2010), to draft a graphical representation of a situation-context implies necessarily, to establish a relationship between two universes. In the universe of situation- context we have a language that involves quantities and concepts whose meanings are treated in different ways: simply (in popular language, without concern about different ways of their existence, etc.), and more rigorous and accurate form (in scientific language). In the universe of graphics, we have a language coded in feature and numbers, which communicates the behaviour of a quantity that characterizes the state of a system that it represents.

Establishing a connection between these two universes requires a certain cognitive potential which depends, not only on the individual's experience with the given situation-context, in terms of the individual's familiarity with the information presented (Junglenn \& Del Pinto, 2009, p.11), but also on the understanding that the individual has relevant conceptual aspects of the behaviour of the involved quantities, and the standard of interpretation of graph construction in the scientific system in which 
the two universes are inserted.

Consequently, activity to create a graphic of a situation-context has not been easy for many students because, according to Costa (2010, p. 139), this activity involves the mobilization of knowledge and resources that are often not visible to the student, and also depend, in some way, on some forms of interpretation. It is precisely this intellectual activity that leads to the development of students' graphic awareness.

In the view of Duval $(2003,2012)$, a consistent analysis of the difficulties of the students, from cognitive point of view in situations of creating graphic, for example, should be in the production system of semiotic representation register. This is because, the replacement of an expression or representation by another that it is equivalent referentially, is the central cognitive process in mathematical activity.

The replacement of a representation by another equivalent referentially to it is called change of representations register. The change of representations register can be done in two ways, known as "treatment" or "conversion". Treatment refers to the transformation of representations made within the same system; whereas "conversion" is the transformation of representations from one register to another target register, while retaining same reference objects (Duval, 2003, p. 14-15).

According to these definitions, the development of graphic awareness from the activity of construction of the graphic draft of a given situation-context, lies in the "conversion" domain. On the cognitive point of view, Duval (2003, p.16) refers to the conversion activity as the fundamental activity of transformation in mathematics, because it leads to the mechanisms underlying the understanding of mathematical knowledge area.

To perform a conversion of a register of representation to another, it is necessary to articulate between specific cognitive variables to the operation of each of the registers, because they are for determining the units of meaning relevant to each register. The difficulty of many students in mathematics lies precisely in inability to recognize the specific cognitive variables and carry out proper articulation. This difficulty grows when it requests, particularly, to convert a situation-context represented in natural language to corresponding representation in graphic design; because, in the perspective of this author, this passage touches a complex set of operations to designate objects (Duval, 2003, p. 17, 18).

The difficulty above can be explained within the prespective which Duval (2012, p. 99) calls the cognitive possibility of substitution between two expressions equivalent referentially, founded in the following two independent relations between two expression: relationship of reference equivalence and relationship of semantic congruence ${ }^{l}$.

During mathematical activity, the spontaneous functioning of the thinking of most stundents tend to follow priority the semantic congruence. However, in converting the referencial equivalence is not essentially reached by the semantic convergence. A jump is required for the substitution of at least one register that belongs to a semantic network with a register that belongs to another semantic network. It is in this jump where students encounter an obstacle to overcome, according to Duval (2012, p.101).

\section{Research Methodology}

The study consisted of analysis of data obtained from a questionnaire submited to a group of 30 students of the Pedagogical University - Beira Campus, consisting of 21 students of the Mathematics course (11 of the 1st year and 10 of the 2nd year) and 9 of the 2nd year of the Physics course.

The questionnaire was composed of 4 activities. The first one was a graph and a question with three alternative answers on a situation-context. The purpose of this first activity was to diagnostic the students' knowledge about the relationship between height and inclination, according to the answer and justification given to the question. The remaining three activities were

\footnotetext{
${ }^{1}$ The relationship of reference equivalence is the possibility of two expressions that refer to the same object or not, or whether or not to say the same thing. A relation of semantic congruence refers to the sense/meaning: if the two expressions keep or not the same semantic meaning.
} 
constituted, each one, by a situation-context of familiarity of students, followed by several statements - elements which are the cognitive variables - expressing the possible relative positions of the parts of a graph, where some of them corresponded to the given situation-context. The students were asked to mark the alternatives that they thought correct, and then had to present the graphic of that situation-context.

The purpose of each of the last three activities was to evaluate the students' capacity to establish the conversion of the situationcontext into graphic register. The level of articulation that each student established between the statements selected was revealed by the grafic register presented. The development of graphic awareness is measured in the progressive performance of students in these last three activities.

\section{Results and Discussion}

The questionnaire was formed by two categories: the first category of the activities 1 and 2, essentialy aimed to diagnostic the knowledge of the students in this chapter. The second category, consisting of activities 3 and 4, is the one that attended the general objective of this study.

\subsection{Results of Activity 1}

The activity 1 measured the capacity of students to recognize the Variation of the magnitude of the dependent variable as a function of the slope of the graph in a Cartesian system.

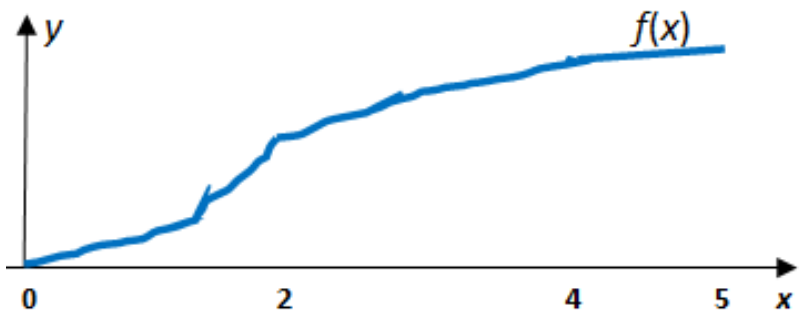

Suppose the graph of $f(x)$ represent the distance travelled by a fly, as a function of time $x$.

Mark $\mathbf{X}$ on the appropriate time interval:

- The fly was fastest in the time interval: 0 to $2 \square \quad 2$ to $4 \square \quad 4$ to $5 \square$

Justify your answer

Figure 1. Graph of distance travelled by a fly.

Only $36.6 \%$ of the students gave correct answer and justifications (13.3\% students of Mathematics and 23.3\% of Physics); like the following: "between the interval of 0 to 2 it is verified that there is less time wasted and the rapid growth of distance, whereas after the time 2 the fly wasted more time and the low growth of distance"; "the fly was faster at the time interval of 0 to 2 because it is when it flew higher and did not waste much time".

The ramaining $63.4 \%$ had, or the correct option, but without justification or wrong reasons $(33.4 \%)$, or incorrect answer without justification or wrong reasons (30\%). Some of the justifications are absurd, such as:

"The fly was faster in the range 0 to 2 because it marked a curve point when it reached point 2";

"the fly was faster in the range of 2 to 4 because it is in this interval that the graph increases or grows".

Others reveal that the student is not aware of what he is trying to say; for example:

"in 0 to 2 , the fly speed increases with increasing time";

"in the interval from 0 to 2 the graph is increasing, in that it represents the distance travelled by the fly".

However, despite the percentage differences, the variable "course" did not have a significantly influence to the results in this activity.

This results leads to conclude that most students cannot perceive, even seeing the figure, that the magnitude of the dependent variable varies directly with the graph slope. However, the magnitude of dependent variable and graph slope are critical 
variables for the task of converting, for the development of the graphic awareness.

\subsection{Results of Activity 2}

In this activity the following situation-context was given:

\section{Put ice cubes in a glass of warm water, and leave it on a table}

First, the student discribed the temperature variation of the water with ice in the cup versus time, and then, constructed a graph which represents this phenomenon.

No student $(0.0 \%)$ was able to present a description and correct graphic. Only 1 student $(3.3 \%)$ presented an accurate description and a more or less correct graph: "at first the water is lukewarm, then its temperature will lower until it reaches its minimum degree, and then it will rise until it becomes warm again". And, presented a graph like the following:

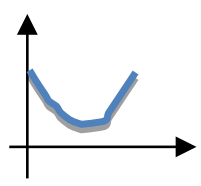

$13.3 \%$ of the students ( 4 of Mathematics and 1 of Phisic) presented a more less correct graph (figure 2), but with semi-correct description, like this:

"the temperature of the water in the glass will decrease rapidly when the amount of ice in the water increases, and will be slow when it is smaller".

\section{Figure 2}

The remaining $83.4 \%$ of the students presented descriptions that barely expressed a plausible judgment about the variation of the water temperature in the glass, and simply increasing or simply decreasing graphs. We have for example the following description:

"In the first few minutes, the ice melts faster with respect to the time when it begins to acquire equilibrium, from where time will spend more and the ice will melt slowly".

Here too, the variable "course" did not have a significant influence on the results.

In general, students have shown great difficulties in describing a situation-context phenomenon of their practical and scientific repertoires; consequently, could not draw a corresponding graph. The results of the activity 1 and 2 indicate a most poor performance of the students. The students difficulties were to create a visual image of specific elements (cognitive variables), relevant to the conversion operation of a situation-context to graphic register.

\subsection{Results of Activities 3 and 4}

The activities 3 and 4 were adopted, specifically to meet the objective of this study.

Indeed, to measure how the student can create a visual image of the specific elements (cognitive variable) and to make conversion, they were given, in each activity, several alternatives, according to the parties of situation-context phenomena.

So, the activities 3 and 4 were structured with specific objectives to assess the ability of the students in:

(a) Recognize the specific cognitive variables, which are relevant to reference equivalence between the situation-context and graphc register;

(b) To convert a situation-context into graphic register, by articulating the recognized cognitive variables between the two registers. This capacity is measured by the relation between the response in (a) and graph sketched.

\subsection{Results of Activities 3}

The task was as follows:

Consider the situation-context: 
To go to school, the way that John runs is, first a straight line horizontally, then it ascend, and finally it descends.

Select the statements that you think are correct, assigning by a $\mathrm{X}$ at the right in the table 1 (Note: inclination $=$ slope in relation with the horizontal line).

Table 1. Statements about the graphic of traveled distance $\mathrm{x}$ time.

\begin{tabular}{|c|c|}
\hline $\begin{array}{l}\text { Kind of the } \\
\text { way taken }\end{array}$ & $\begin{array}{l}\text { Statemants about the graphic of traveled } \\
\text { distance as a function of time }\end{array}$ \\
\hline \multirow{5}{*}{$\begin{array}{l}\text { Horizontal } \\
\text { straight line }\end{array}$} & $\begin{array}{l}\text { The graph is not growing, nor is decreasing (is } \\
\text { parallel to the } x \text { axis) }\end{array}$ \\
\hline & The graph is increasing and very inclined \\
\hline & The graph is increasing and little inclined \\
\hline & The graph is decreasing and very inclined \\
\hline & The graph is decreasing and little inclined \\
\hline \multirow{4}{*}{ Ascent } & The graph is increasing and very inclined \\
\hline & The graph is increasing and little inclined \\
\hline & The graph is decreasing and very inclined \\
\hline & The graph is decreasing and little inclined \\
\hline \multirow{4}{*}{ Descent } & The graph is increasing and very inclined \\
\hline & The graph is increasing and little inclined \\
\hline & The graph is decreasing and very inclined \\
\hline & The graph is decreasing and little inclined \\
\hline
\end{tabular}

Now, build a graphic draft representing the distance y travelled by John to school, as function of time $\mathrm{t}$ spent.

Only 2 students (6.7\%) indicated the good alternatives and presented a proper graphic draft. Four students (13.3\%) selected wrong alternatives and drew the correspondents' graphic sketches.

However, $30 \%$ of the students selected wrong alternatives and also presented incorrect graphical sketches, which did not correspond to the chosen alternatives. It is difficult to understand here how these students made the link between the alternatives chosen to obtain the graph presented in each case.

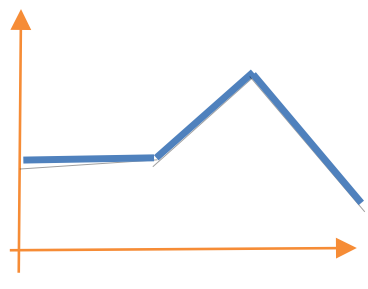

A graph of semantic congruence

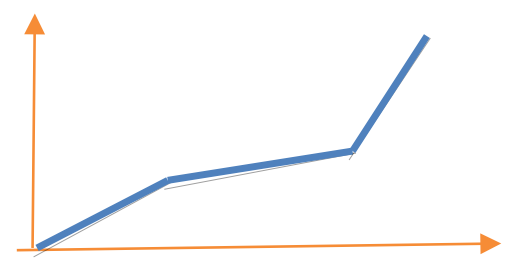

A correct graph

Figure 3. A graph of semantic congruence and a correct graph.

A result to note is that $50 \%$ of the students chose exactly those alternatives which correspond to the semantic congruence with the kind of way, and presented a graph in accordance with these alternatives (horizontal line, growing line, and, decreasing line). So, the semantic congruence was the factor that decisively influenced the thinking of half the students, consequently, they didn't reach the reference aquivalence (Figure 3).

Considering that semantic congruence does not produce referential equivalence in this case, we can conclude that it is about $80 \%$ 
of the students who could not make the connection between the chosen alternatives to obtain the corresponding graph.

\subsection{Results of Activities 4}

The tast was as follows:

Consider the container presented at the right hand (Figure 4). As you are watching, the container is a funnel, with a closed bottom.

\section{Slowly, put water into the funnel, until it is completely full}

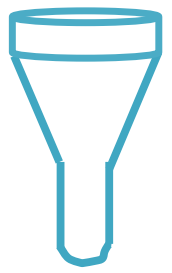

Figure 4

(a) Three parts of the funnel are distinguishable, according to the figure given in the following Table 2 . Indicate the statement you think is true. Use a X to select your answer.

Table 2. Statements about the variation of the water surface area and height.

\section{Statements about the variation of the water surface area in the funnel during the filling process, depending on the height reached by the water}

\begin{tabular}{|c|c|}
\hline \multirow{3}{*}{ Top } & $\begin{array}{l}\text { The surface area of the water increases in the same proportion of the increase in height of } \\
\text { the water }\end{array}$ \\
\hline & $\begin{array}{l}\text { The surface area of the water increases in a proportion greater than the increase in height } \\
\text { of the water }\end{array}$ \\
\hline & The surface area of the water does not vary as the height increase \\
\hline \multirow{4}{*}{$\begin{array}{l}\text { Middle } \\
\text { part }\end{array}$} & $\begin{array}{l}\text { The surface area af the water increases in the same proportion of the increase in height of } \\
\text { water }\end{array}$ \\
\hline & $\begin{array}{l}\text { The surface area of the water increases in proportion greater than the increase in height } \\
\text { of the water }\end{array}$ \\
\hline & $\begin{array}{l}\text { The surface area of the water increases in the proportion lower than the increase in } \\
\text { height of the water }\end{array}$ \\
\hline & The surface area of the water does not vary as the height increases \\
\hline \multirow{4}{*}{$\begin{array}{l}\text { Lower } \\
\text { part }\end{array}$} & $\begin{array}{l}\text { The surface area of the water increases in the same proportion of the increase in height of } \\
\text { the water }\end{array}$ \\
\hline & $\begin{array}{l}\text { The surface area of the water increases in proportion greater than the increase in height } \\
\text { of the water }\end{array}$ \\
\hline & $\begin{array}{l}\text { The surface area of the water increases in proportion lower than the increases in height } \\
\text { of water }\end{array}$ \\
\hline & The surfce area of the water does not vary as the height increase \\
\hline
\end{tabular}


(b) Now, construct a graph that represents the variation of the area A of the water surface in the funnel during filling, as a function of height $h$ reached by the water.

$23 \%$ of the students indicate the correct alternatives and presented appropriate graphic sketches (Figure 5, (I)).

$10 \%$ of the students could provide a correct graphic, but with incorrect choice of alternatives, and $6.7 \%$ chose the correct alternatives, but showed an incorrect graph (figure 5 (II)). It appears that some students can build a graphic of a situationcontext, intuitively, without, however, being able to reveal the cognitive variables used. This phonomenon may indicate that, probably, some students made a random choice, or they cannot make the connection between the alternatives and the graph.

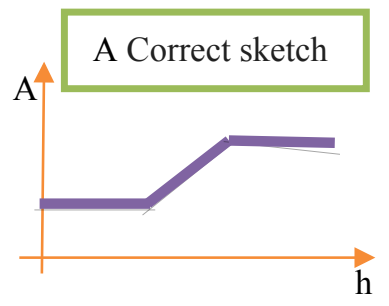

(I)

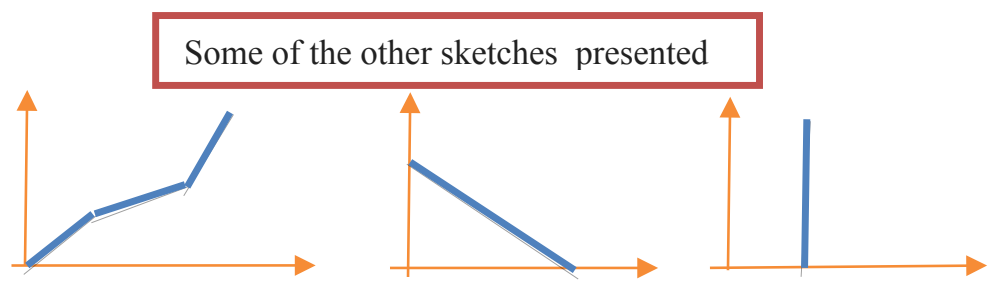

(II)

Figure 5

Overall, $23 \%$ of students chose non-appropriate alternatives and were able to correctly sketch the charts corresponding to each choice. These results reveal that, although they did not choose the right alternatives, these students can make the connection between the alternatives and the graph.

They are, therefore, about $54 \%$ of students who choose (incorrect) alternatives and cannot sketch the corresponding graphs.

\section{Conclusions}

All the results show very low levels of student performance in the activities. This means that students in the first years of Maths and Physics courses at university still have difficulties to convert a situation-context to a graph register.

Even being given the set of possible cognitive variables, it was found that many students failed to recognize and articulate the specific cognitive variables between the two registers of functional representation.

From the results of activities 1 and 2, we can imagine that the difficulties for this purpose are due to poor understanding of the direct relationship between the magnitude of dependent variable and graph inclination, and the weak development of graphical awareness, through the students have studied a lot of functions.

Most students tend to use the semantic congruence to do the conversion of a situation-context to graphic register. This may mean that these students have not conceived a graph as a figure that establishes a relation between two variables, and what should prevail in a conversion is the reference equivalence of these relations in two registers.

Therefore, all results of this study, considered individually activity by activity, indicate a worrying situation of students' learning about functions and their representations.

However, if the results are considered together, we note an important result:

From the activity 3 to the activity 4, there was a growth performance of the students in about $16.3 \%$ (an increase from $6.7 \%$ to $23 \%$ ) in the activity of converting a situation-context into a graph. This increase can be considered significant in this type of activity, because, according to Duval (2003), this type of conversion - from natural language, as the case of situation-context, to a graphic register - generally has been very difficult for students.

On the other hand, there is a growth of about $9.7 \%$ (from $13.3 \%$ to $23 \%$ ) in the students' ability to make the connection 
between alternatives and corresponding graph; and a decrease of about $26 \%$ (from $80 \%$ to $54 \%$ ) in the use of intuition or randomness to sketch a graph of a situation-context.

Therefore, on average there was an increase of about $16 \%$ in student performance. The negative results of this study, only may indicate that the conversion activities of situation-context to graphic register were unfamiliar and not yet on the domain of the students' knowledge.

These results of relative growth of students' performance reveal that there has been a development of their graphic consciences, by the methodological quality of the research approach used in this study. It was noticed that the methodology adopted in the design and structuring of the activities in this research can contribute significantly to the rapid development and growth of graphical awareness of students.

\section{References}

Bell, A. \& Janvier, C (1981). The interpretation of Graphs Representation Situation. Learning of Mathematics, 2, 34-42.

Braga, C. (2006). Função: a alma da matemática. São Paulo, Annablume.

Costa, A. M. V. (2010). A interpretação de gráficos de movimento. Dissertação de Mestrado. Faculdade de Educação de UFMG. Belo Horizonte.

Da Silva, M. V. (2007). Dificuldade de representação gráfica quando apresentado num contexto real. In Anal de IX ENEM - Encontro Nacional de Educação Matemática. Belo Horizonte.

Duval, R. (2003). Registos de representações semióticas e funcionamento cognitico da cmpreensão em matemática. In Aprendizagem em Matemática. Registos de representação semiótica. Silvia Dias A. Machado (org.). São Paulo. Papirus.

Duval, R. (2011). Gráficos e equações: a articulação de dois registos. In REVEMAT - Revista electrónica de matemática. 6(2), 96-112. Florianópolis.

Duval, R. (2012), Diferenças semanticas e coerência matemática. In REVEMAT - Revista electrónica de matemática. 7(1), 97-117. Florianópolis.

Jungkenn, M. A. T. \& Del Pinto, J. C. (2009). Analisando a capacidade de estudantes concludentes do ensino médio fundamental de enterpretar informações de gráficos e tabelas. In Anal de ENPEC - Encontro Nacioanl de Pesquisa em Educação em Ciências. Florianópoles. 